\title{
Disturbed Experience of Self: Psychometric Analysis of the Self-Experience Lifetime Frequency Scale (SELF)
}

\author{
Henriëtte Dorothée Heering ${ }^{c}$ Saskia Goedhart ${ }^{\mathrm{e}}$ Richard Bruggeman ${ }^{\mathrm{a}}$ Wiepke Cahn ${ }^{\mathrm{b}}$ \\ Lieuwe de Haanc René S. Kahn ${ }^{b}$ Carin J. Meijerc Inez Myin-Germeys ${ }^{d} \quad$ Jim van Os ${ }^{d, f}$ \\ Durk Wiersma ${ }^{a}$ \\ ${ }^{a}$ Department of Psychiatry, University Medical Center Groningen, University of Groningen, Groningen, ${ }^{\mathrm{b}}$ Department of \\ Psychiatry, University Medical Center Utrecht, Rudolf Magnus Institute of Neuroscience, Utrecht, ' ${ }^{\circ}$ epartment of Psychiatry, \\ Academic Medical Centre, University of Amsterdam, Amsterdam, ${ }^{\mathrm{d}}$ Maastricht University Medical Centre, South Limburg \\ Mental Health Research and Teaching Network, EURON, Maastricht, and ${ }^{\mathrm{e} Z a a n s}$ Medisch Centrum, Zaandam, The Netherlands; \\ ${ }^{f}$ Department of Psychosis Studies, Institute of Psychiatry, King's College London, London, UK
}

\section{Key Words}

Self-Experience Lifetime Frequency scale · Self-disturbance · Depersonalization · Psychotic disorder

\begin{abstract}
Background: Schizophrenia is characterized by positive and negative symptoms, but recently anomalous self-experiences, e.g. exaggerated self-consciousness (hyperreflectivity), receive more attention as an important symptom domain in schizophrenia patients. The semi-structured interview, the Examination of Anomalous Self-Experience (EASE) [Psychopathology 2005;38:236-258], examines experiences of a disturbed sense of self in a sophisticated but time-consuming manner. Therefore, we proposed the Self-Experience Lifetime Frequency scale (SELF), an instrument intended to screen for self-disturbance phenomena. Here we compared scores of patients, their siblings and healthy controls on the SELF. Methods and Sampling: The SELF is composed of a validated screener for symptoms of depersonalization complemented by questions covering several other domains of self-disturbance. A total of 426 patients with a psychotic disorder, 526 of their unaffected siblings, and 297 healthy con-
\end{abstract}

\section{KARGER}

E-Mail karger@karger.com www.karger.com/psp

\section{C) 2016 The Author(s) \\ Published by S. Karger AG, Basel 0254-4962/16/0492-0069\$39.50/0} This article is licensed under the Creative Commons Attribution-
NonCommercial-NoDerivatives 4.0 International License (CC BYNC-ND) (http://www.karger.com/Services/OpenAccessLicense). Usage and distribution for commercial purposes as well as any distribution of modified material requires written permission. trols completed the SELF. Patients' scores on the 12 items of the SELF were subjected to an explorative principal axis factor analysis (PAF); composite scores on factor components were compared between the three participant groups. $\boldsymbol{R e}$ sults: The PAF revealed two components, explaining 43.9 and $9.5 \%$ of variance, respectively. The first component represents a disturbance of self-awareness; the second component reflects (milder forms of) diminished self-affection or depersonalization. The two components of the SELF revealed good internal consistency (component 1, $a=0.88$; component 2, $a=0.79 ; \rho=0.85$ ). Patients showed significantly higher scores on both factor components in comparison with both siblings and controls. No significant differences were found between siblings and controls. Conclusions: The findings of the current study suggest that the SELF comprises two components of self-disturbance. Patients reported more (severe) symptoms of self-disturbance on both components, suggesting that it is feasible to screen for selfdisturbance phenomena in patients with psychotic disorders with the SELF. Screening for symptoms of self-disturbance is important since these symptoms are associated with suffering and, moreover, these phenomena may mark the transition from intact to aberrant reality testing.

(c) 2016 The Author(s)

Published by S. Karger AG, Basel

Henriëtte Dorothée Heering

Department of Psychiatry, Academic Medical Centre

Meibergdreef 5

NL-1105 AZ Amsterdam (The Netherlands)

E-Mail J.Heering@ggzingeest.nl 


\section{Introduction}

Altered self-experiences are increasingly perceived as an important disturbance in schizophrenia [1-6]. A disturbed self-experience can be most puzzling and frightening to patients, and may lead to withdrawal from social contact $[7,8]$. Subtle experiences of self-disturbance have already been found in the prodromal phase of schizophrenia $[9,10]$, and they have been recognized as a risk factor for transition to psychosis in subjects at 'ultra-high risk' for the disorder [11].

From a phenomenological perspective altered self-experience is considered a consequence of abnormalities in self-awareness. Various interrelated experiences of selfdisturbance have been described, for example a disturbed stream of consciousness, a disturbed sense of corporeality and loss of ego boundaries. Also, symptoms of depersonalization and derealization are considered as signs of self-disturbance by phenomenologically oriented researchers $[2,4,12]$. Two specific disturbances in selfawareness, namely hyperreflectivity and diminished selfaffection, are hypothesized to underlie several symptoms of schizophrenia, such as thought insertion and anhedonia $[2,4,12]$. Hyperreflectivity refers to a phenomenon of exaggerated self-consciousness [1], in which aspects of the self and the world around us, normally implicitly perceived, become object of intense observation and thought [13]. Diminished self-affection refers to a diminished intensity or vitality of subjective presence: the self is no longer automatically and at a prereflective level present in every act of awareness. As a result subjective experience is no longer automatically experienced as immediately one's own $[4,14]$. For a comprehensive and elaborate overview of these and other symptoms of self-disturbances we refer to Parnas et al. [2, 4, 14].

The detailed assessment of disturbed self-experiences needs extensive expertise. With the Examination of Anomalous Self-Experience (EASE), Parnas et al. [2] have developed a semi-structured interview for this purpose. The EASE is without doubt the most comprehensive instrument to assess these phenomena associated with disturbed self-experience. However, it is time-consuming, making the EASE not functional for use in large-scale studies or in clinical settings.

In everyday practice clinicians often encounter patients who experience self-disturbances. A feasible and less elaborate instrument for screening self-disturbance phenomena would facilitate addressing these symptoms. Also, for usage in large-scale studies a short screener for self-disturbances would be useful. The Self-Experience Lifetime Fre- quency scale (SELF; in Dutch: Zelfwaarnemingsstoornissen Ernst- en Lifetime Frequentieschaal, ZELF) was constructed by including items from a short, reliable and valid instrument to measure depersonalization (Depersonalization Severity Scale, DSS) [15], complemented with several questions based on theEASEand theComprehensive Assessment of At-Risk Mental States (CAARMS) [16]. The reason for using the DSS is that previous research has shown that symptoms of depersonalization disorder (DSM-IV code 300.6) resemble those of self-disturbance [1]. However, feelings of depersonalization also frequently occur in the healthy population (30-70\% in healthy adolescents) [17], as well as a comorbid symptom in the general psychiatric population (50-80\%) [17]. Therefore, we added several questions concerning self-disturbance phenomena based on the EASE and the CAARMS [16] that may be more specific to experiences of patients with psychotic disorders.

Here, we describe the development and factor structure of the SELF as well as its psychometric properties. Two non-clinical samples were included to determine the presence of experiences of self-disturbance in one population with genetic risk for developing psychosis (siblings) and one population unrelated to psychosis (healthy control group). Genetic determinants of psychotic disorders have been identified as predisposed for subclinical psychotic experiences [18]. We therefore expected more (severe) symptoms of self-disturbances in siblings of patients with a psychotic disorder compared to healthy controls, albeit at a subclinical level.

\section{Methods}

Sample

We included a subsample of a larger group of patients with a psychotic disorder, as recruited for the Genetic Risk and Outcome of Psychosis (GROUP) study. In this naturalistic follow-up study with three assessment points within a 6-year time span, 1,120 patients with a psychotic disorder, 1,057 of their siblings, 919 of their parents and 590 unrelated control subjects were included. The SELF was included at the third assessment with 1,249 participants (426 patients, 526 healthy siblings and 297 healthy controls). For the GROUP study, participants were selected from geographical areas in the Netherlands and Belgium. Patients were identified by experienced clinicians whose existing caseloads were screened by means of inclusion and exclusion criteria. The procedure of recruitment, the inclusion and exclusion criteria and characteristics of the GROUP study have been described in detail elsewhere [19].

\section{Development of the SELF}

In the selection of individual items for the SELF, our goal was to cover the wide range of experiences of self-disturbance, guided by current clinical knowledge. Because the concept of self-disturbance demonstrates a large overlap with symptoms of depersonalization
Heering et al. 
Table 1. Self-Experience Lifetime Frequency scale (SELF)

\begin{tabular}{|c|c|c|c|}
\hline & \multicolumn{2}{|c|}{$\begin{array}{l}\text { How often in your life have you } \\
\text { had the described experience? } \\
\text { Rank A }\end{array}$} & \multirow{2}{*}{$\begin{array}{l}\text { How distressed were you } \\
\text { by this experience? } \\
\text { Rank B } \\
\square 0 \text { Not distressed } \\
\square 1 \text { Mildly distressed } \\
\square 2 \text { Moderately distressed } \\
\square 3 \text { Very distressed } \\
\square 4 \text { Severely distressed }\end{array}$} \\
\hline $\begin{array}{l}\text { 1. Have you felt as if you were standing next } \\
\text { to yourself or watched yourself like looking at } \\
\text { someone else or as if in a movie? }\end{array}$ & $\square 0$ Never & $\begin{array}{l}\square 1 \text { Sometimes } \\
\square 2 \text { Regularly } \\
\square 3 \text { Often } \\
\square 4 \text { All the time }\end{array}$ & \\
\hline $\begin{array}{l}\text { 2. Have you felt as if your whole body or } \\
\text { parts of your body were detached or did } \\
\text { not belong to you? }\end{array}$ & $\square 0$ Never & $\begin{array}{l}\square 1 \text { Sometimes } \\
\square 2 \text { Regularly } \\
\square 3 \text { Often } \\
\square 4 \text { All the time }\end{array}$ & $\begin{array}{l}\square 0 \text { Not distressed } \\
\square 1 \text { Mildly distressed } \\
\square 2 \text { Moderately distressed } \\
\square 3 \text { Very distressed } \\
\square \text { 4 Severely distressed }\end{array}$ \\
\hline $\begin{array}{l}\text { 3. Have you felt unreal or like a stranger to } \\
\text { yourself? }\end{array}$ & $\square 0$ Never & $\begin{array}{l}\square 1 \text { Sometimes } \\
\square 2 \text { Regularly } \\
\square 3 \text { Often } \\
\square 4 \text { All the time }\end{array}$ & $\begin{array}{l}\square 0 \text { Not distressed } \\
\square 1 \text { Mildly distressed } \\
\square 2 \text { Moderately distressed } \\
\square 3 \text { Very distressed } \\
\square \text { 4 Severely distressed }\end{array}$ \\
\hline $\begin{array}{l}\text { 4. Have you looked in the mirror and felt } \\
\text { disconnected from your own image? }\end{array}$ & $\square 0$ Never & $\begin{array}{l}\square 1 \text { Sometimes } \\
\square 2 \text { Regularly } \\
\square 3 \text { Often } \\
\square 4 \text { All the time }\end{array}$ & $\begin{array}{l}\square 0 \text { Not distressed } \\
\square 1 \text { Mildly distressed } \\
\square 2 \text { Moderately distressed } \\
\square 3 \text { Very distressed } \\
\square \text { 4 Severely distressed }\end{array}$ \\
\hline $\begin{array}{l}\text { 5. Have you felt like you were in a dream or } \\
\text { just going through the motions? }\end{array}$ & $\square 0$ Never & $\begin{array}{l}\square 1 \text { Sometimes } \\
\square 2 \text { Regularly } \\
\square 3 \text { Often } \\
\square 4 \text { All the time }\end{array}$ & $\begin{array}{l}\square 0 \text { Not distressed } \\
\square 1 \text { Mildly distressed } \\
\square 2 \text { Moderately distressed } \\
\square 3 \text { Very distressed } \\
\square \text { 4 Severely distressed }\end{array}$ \\
\hline $\begin{array}{l}\text { 6. Have you felt as if your speech, voice, } \\
\text { movements or behaviour were somehow } \\
\text { not controlled by you or not connected } \\
\text { to you? }\end{array}$ & $\square 0$ Never & $\begin{array}{l}\square 1 \text { Sometimes } \\
\square 2 \text { Regularly } \\
\square 3 \text { Often } \\
\square 4 \text { All the time }\end{array}$ & $\begin{array}{l}\square 0 \text { Not distressed } \\
\square 1 \text { Mildly distressed } \\
\square 2 \text { Moderately distressed } \\
\square 3 \text { Very distressed } \\
\square \text { 4 Severely distressed }\end{array}$ \\
\hline $\begin{array}{l}\text { 7. Have you felt that your sense of time had } \\
\text { changed, as if time was blocked, cut into } \\
\text { pieces or was altered in some inexplicable way? }\end{array}$ & $\square 0$ Never & $\begin{array}{l}\square 1 \text { Sometimes } \\
\square 2 \text { Regularly } \\
\square 3 \text { Often } \\
\square 4 \text { All the time }\end{array}$ & $\begin{array}{l}\square 0 \text { Not distressed } \\
\square 1 \text { Mildly distressed } \\
\square 2 \text { Moderately distressed } \\
\square 3 \text { Very distressed } \\
\square \text { 4 Severely distressed }\end{array}$ \\
\hline $\begin{array}{l}\text { 8. Have you felt that as if your inner world } \\
\text { of thoughts, fantasies, memories or plans } \\
\text { got mixed up with what happened in reality? }\end{array}$ & $\square 0$ Never & $\begin{array}{l}\square 1 \text { Sometimes } \\
\square 2 \text { Regularly } \\
\square 3 \text { Often } \\
\square 4 \text { All the time }\end{array}$ & $\begin{array}{l}\square 0 \text { Not distressed } \\
\square \text { 1 A little distressed } \\
\square 2 \text { Mildly distressed } \\
\square 3 \text { Moderately distressed } \\
\square \text { 4 Severely distressed }\end{array}$ \\
\hline $\begin{array}{l}\text { 9. Have you felt that your thoughts, feelings } \\
\text { and/or actions were in some way dis- } \\
\text { connected from each other or from yourself? }\end{array}$ & $\square 0$ Never & $\begin{array}{l}\square 1 \text { Sometimes } \\
\square 2 \text { Regularly } \\
\square 3 \text { Often } \\
\square 4 \text { All the time }\end{array}$ & $\begin{array}{l}\square 0 \text { Not distressed } \\
\square 1 \text { Mildly distressed } \\
\square 2 \text { Moderately distressed } \\
\square 3 \text { Very distressed } \\
\square \text { 4 Severely distressed }\end{array}$ \\
\hline $\begin{array}{l}\text { 10. Have you felt that common sense of the } \\
\text { world around you had been lost? }\end{array}$ & $\square 0$ Never & $\begin{array}{l}\square 1 \text { Sometimes } \\
\square 2 \text { Regularly } \\
\square 3 \text { Often } \\
\square 4 \text { All the time }\end{array}$ & $\begin{array}{l}\square 0 \text { Not distressed } \\
\square 1 \text { Mildly distressed } \\
\square 2 \text { Moderately distressed } \\
\square 3 \text { Very distressed } \\
\square \text { 4 Severely distressed }\end{array}$ \\
\hline
\end{tabular}


Table 1 (continued)

\begin{tabular}{|c|c|c|c|}
\hline & \multicolumn{2}{|c|}{$\begin{array}{l}\text { How often in your life have you } \\
\text { had the described experience? } \\
\text { Rank A }\end{array}$} & \multirow{2}{*}{$\begin{array}{l}\text { How distressed were you } \\
\text { by this experience? } \\
\text { Rank B } \\
\square 0 \text { Not distressed } \\
\square 1 \text { Mildly distressed } \\
\square 2 \text { Moderately distressed } \\
\square 3 \text { Very distressed } \\
\square 4 \text { Severely distressed }\end{array}$} \\
\hline $\begin{array}{l}\text { 11. Have you ever had the disturbing } \\
\text { experience that you had to think about the } \\
\text { most self-evident things, such as your } \\
\text { thinking, everyday actions or objects? }\end{array}$ & $\square 0$ Never & $\begin{array}{l}\square 1 \text { Sometimes } \\
\square 2 \text { Regularly } \\
\square 3 \text { Often } \\
\square 4 \text { All the time }\end{array}$ & \\
\hline $\begin{array}{l}\text { 12. Do you feel that the relationship between } \\
\text { yourself and your surroundings has changed } \\
\text { profoundly and fundamentally because of } \\
\text { having the above-mentioned experience(s)? }\end{array}$ & $\square 0$ Never & $\begin{array}{l}\square 1 \text { Sometimes } \\
\square 2 \text { Regularly } \\
\square 3 \text { Often } \\
\square 4 \text { All the time }\end{array}$ & $\begin{array}{l}\square 0 \text { Not distressed } \\
\square 1 \text { Mildly distressed } \\
\square 2 \text { Moderately distressed } \\
\square 3 \text { Very distressed } \\
\square \text { 4 Severely distressed }\end{array}$ \\
\hline
\end{tabular}

Questions 1-6 are translated from the DSS [15], while questions 7-11 were adapted from the EASE [9] and question 12 from the CAARMS [16].

[1], our starting point was the use of an already validated questionnaire on depersonalization. The Cambridge Depersonalization Scale (CDS) [20,21] may at first glance be a good candidate because it is detailed and well substantiated. However, due to its length (29 items) and with the purpose of the present study in mind, the CDS is unsuited for a screener. The DSS [15], however, is also a validated instrument for depersonalization and comprises only 6 items.

Translation

The DSS covers 6 items that assess the severity of depersonalization. We used a forward-backward procedure for translation of the DSS, as used by Bullinger et al. [22] (1998). Firstly, the DSS was translated into Dutch by one of the authors and then translated back into English by a native English/Dutch-speaking psychiatrist without having seen the original DSS. Differences were discussed and a final consensus version was created.

Additional Items.

Six questions (table 1) were added to the DSS covering the specific aspects of self-disturbance (disturbed stream of consciousness, disturbed sense of presence or corporeality and disturbed common sense). Specifically, questions $7-11$ are based on the EASE interview $[2,4,9,10]$. Question 7 covers an aspect of disturbed stream of consciousness and questions 8-10 cover aspects of disturbed sense of presence. Question 11 refers to hyperreflectivity, a condition of exaggerated self-consciousness, in which phenomena that are normally experienced as part of oneself become the object of intense rumination. The EASE defines hyperreflectivity as an 'occasionally excessive or frequent, even chronic, tendency to take oneself or parts of oneself or aspects of the environment as objects of intense reflection' [13,23]. Finally, question 12 was derived from the CAARMS: Delusional Mood and Perplexity ('Non-Crystallized Ideas') [16] and covered the profound alteration between self and the world as described by patients as a result of experiencing self-disturbance [7, 24]. Patients were asked to report on a 5 -point Likert scale about the life-time frequency and level of burden of these 12 items. Frequency scores range from 0 (never) to 4 (continuously) and the level of distress from 0 (no distress) to 4 (extremely burdensome). A total score was calculated by adding the scores of both frequency and distress for each item.

\section{Analyses}

Factor Structure of the SELF

For the factor structure we made use of only patient data, since the SELF is developed to screen for self-disturbance phenomena in patients with a psychotic disorder. Firstly, a total score per item was computed by adding the frequency and distress scores, comparable to the EASE ratings [2]. Next, the scores of the 12 items were subjected to an explorative principal axis factor analysis (PAF) using SPSS 20.0. Only components with an eigenvalue exceeding 1 were considered as valid components. PAF was the rightful exploratory factor analysis, due to the skewed distribution of the data [25]. To facilitate the interpretation of components, oblique rotation (oblimin) was performed. The Kaiser-Meyer-Oklin measure of sampling adequacy should exceed the value of 0.6 $[26,27]$, and Bartlett's test of sphericity should be significant $(\mathrm{p}<$ 0.05 ) for the PAF to be considered appropriate [28]. Internal consistency of components will be calculated by Cronbach's alpha ( $\alpha$ ).

\section{Distribution of Components}

The scores on the components extracted by the PAF of patients, siblings and healthy controls were calculated to two total component scores (containing both frequency and distress scores). We then compared the total component scores between our samples using one-way ANOVAs.

\section{Results}

\section{Sample Description}

A total of 1,249 participants completed the SELF. The patient group consisted of 426 participants (73\% male), 
with a mean age of 34 (SD 7.5) years. A total of $66 \%$ of patients were diagnosed with schizophrenia, $16 \%$ with schizoaffective disorder, $11 \%$ with brief psychotic disorder or psychotic disorder not otherwise specified, $4 \%$ with bipolar disorder, $2 \%$ with schizophreniform disorder and $3 \%$ with other psychotic disorders. The mean age of illness onset was 23 (SD 6.9) years, with a mean illness duration of 14 (SD 4.1) years. The sibling group consisted of 526 participants (45\% male), with a mean age of 35 (SD 8) years. The group of healthy controls consisted of 297 participants (41\% male), with a mean age of 38 (SD 11) years. There was a significant difference in the gender distribution between the groups. Compared to the patient group, controls and siblings were more often female $\left[\chi^{2}(1)=73.4\right.$, $\mathrm{p}<0.0001$ and $\chi^{2}(1)=73.6, \mathrm{p}<0.0001$, respectively].

\section{Distribution of Items in Patients, Siblings and Healthy Controls}

First we explored the response diversity of the SELF per subject group. The patient sample reported most often to be bothered by their 'reality and inner world mixed up' (item 8 ), with $21.5 \%$ of the patient population reporting having experienced this at least regularly, and of this $21.5 \%, 38.4 \%$ reported this caused them at least a moderate level of distress. 'Hyperreflectivity' (item 11) was the second most reported experience, with $23.6 \%$ of patients reporting having experienced this at least regularly, and of this $23.6 \%, 34.2 \%$ reported this caused them at least a moderate level of distress. All other symptoms were experienced regularly by less than $20 \%$ of the patients, which however was still significantly more often than siblings and control subjects.

For siblings and controls, the 'feeling as if they were living in a dream' (item 5) was reported most often, although only $1 \%$ of them reported having experienced this feeling at least regularly, and just $4.8 \%$ felt this to be at least moderately distressing. All other items were experienced even less frequently by siblings and healthy controls, and caused less distress.

\section{Factor Structure of the SELF \\ PAF of the SELF}

We found a Kaiser-Meyer-Oklin value of 0.9 and Bartlett's test of sphericity reached statistical significance $(\mathrm{p}<0.001)$, supporting the factorability of the correlation matrix. The PAF revealed two components with eigenvalues of 5.27 and 1.13, respectively, explaining 43.9 and $9.5 \%$ of the variance. The scree plot confirmed the presence of two components, with a clear break after the second component. Oblimin rotation was performed to aid
Table 2. PAF: rotated component matrix $(n=426)$

\begin{tabular}{lcc}
\hline & $\begin{array}{l}\text { Compo- } \\
\text { nent 1 }\end{array}$ & $\begin{array}{l}\text { Compo- } \\
\text { nent 2 }\end{array}$ \\
\hline Eigenvalue & 5.27 & 1.13 \\
\% variance accounted for & 43.9 & 9.5 \\
Cronbach's a & 0.88 & 0.79 \\
\hline 5. Feeling as if in a dream & 0.427 & 0.378 \\
6. Loss of control & 0.379 & 0.294 \\
7. Disturbed feeling of time & 0.574 & 0.117 \\
8. Reality and inner world mixed & 0.721 & 0.037 \\
9. Emotions and thoughts disconnected & 0.494 & 0.155 \\
10. Loss of common sense & 0.611 & 0.078 \\
11. Hyperreflectivity & 0.756 & -0.028 \\
12. Profound change between self and world & 0.761 & -0.146 \\
1. Observe yourself from outside & -0.003 & 0.595 \\
2. Detached from own body & -0.027 & 0.563 \\
3. Feeling unreal & 0.049 & 0.742 \\
4. Problems mirror reflections & 0.061 & 0.512 \\
\hline
\end{tabular}

the interpretation of the two components. Table 2 provides an overview of item factor loadings per component. Inspection of the items loading on the first component after rotation suggests that component 1 represents symptoms which could be described as more 'estranging' or reflecting substantial disturbance of self-awareness (such as the experience of disconnection between own thought and self or the experience of 'loss of common sense'). Component 2 reflects (milder forms of) diminished self-affection or depersonalization, such as the experience of being disconnected or dissociated from one's body. Items 5 and 6, originating from the DSS, loaded moderately on both components, suggesting an overlap between the two components.

The two components of the SELF revealed good internal consistency: Cronbach's $\alpha=0.88$ for component 1 and 0.79 for component 2 , with a correlation between the two components of $\rho=0.85$.

\section{Distribution of Components}

Patients showed significantly higher total scores on both components in comparison with both siblings and controls (component 1: $\mathrm{F}_{2,1248}=375.1, \mathrm{p}<0.0001$ ); component 2: $\left.F_{2,1,248}=217.3, p<0.0001\right)$. No significant differences were found between siblings and controls on either of the components (fig. 1,2) 


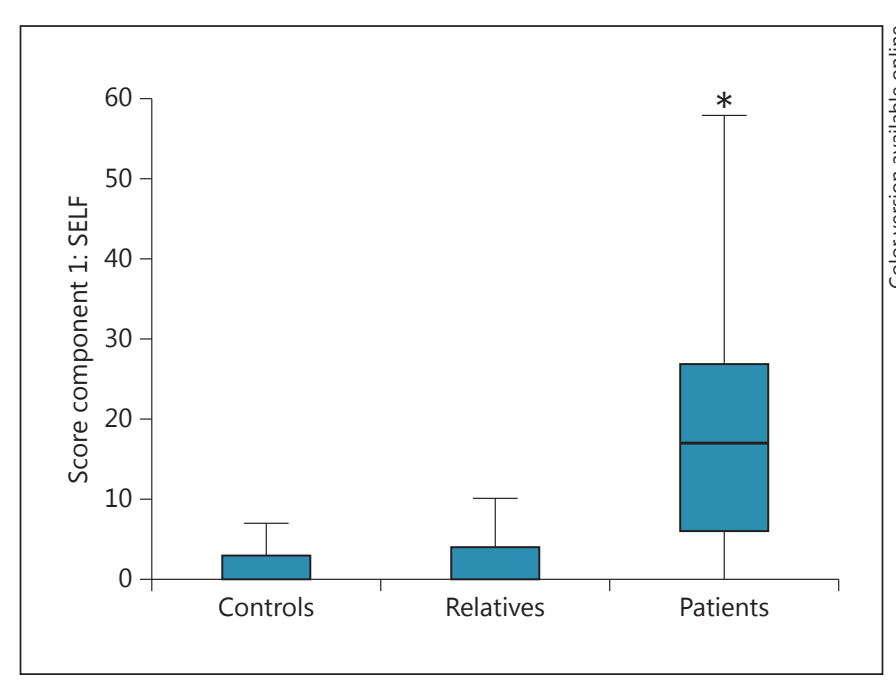

Fig. 1. Distribution of scoring component 1 per participant group. $* \mathrm{p}<0.0001$, mean significant difference.

\section{Discussion}

The present study was designed to take the first steps in the psychometric evaluation of a newly developed screening instrument, the SELF, for complaints of selfdisturbance in patients with a psychotic disorder. The SELF showed an internal factor structure with two components, both with good internal reliabilities (Cronbach's $\alpha$ of 0.88 and 0.79 , respectively) and with a high correlation between the two components $(\rho=0.85)$. The components broadly reflect the two 'sources' we used to compose the SELF, and with this two-factor structure we captured two interrelated aspects of self-disturbance. The first component contains the experiences of a disturbed self-awareness, i.e. the more estranging phenomena known to be associated with schizophrenia [2], such as loss of common sense or the feeling that time has lost its natural course (item 7). This component also contains the items most frequently reported by patients: the feeling that reality and the inner world have gotten mixed up and experiences of hyperreflectivity. Hyperreflectivity has been described as one of two core aspects of altered selfawareness in psychotic patients, together with diminished self-affection [23]. The first component of the SELF could be interpreted as a representative of these two properties, with item 11 representing experiences of hyperreflectivity and items 5-10 experiences in which own thought, emotion or action no longer have the prereflective sense of 'my experience'. The second component of the SELF contains items referring to symptoms of deper-

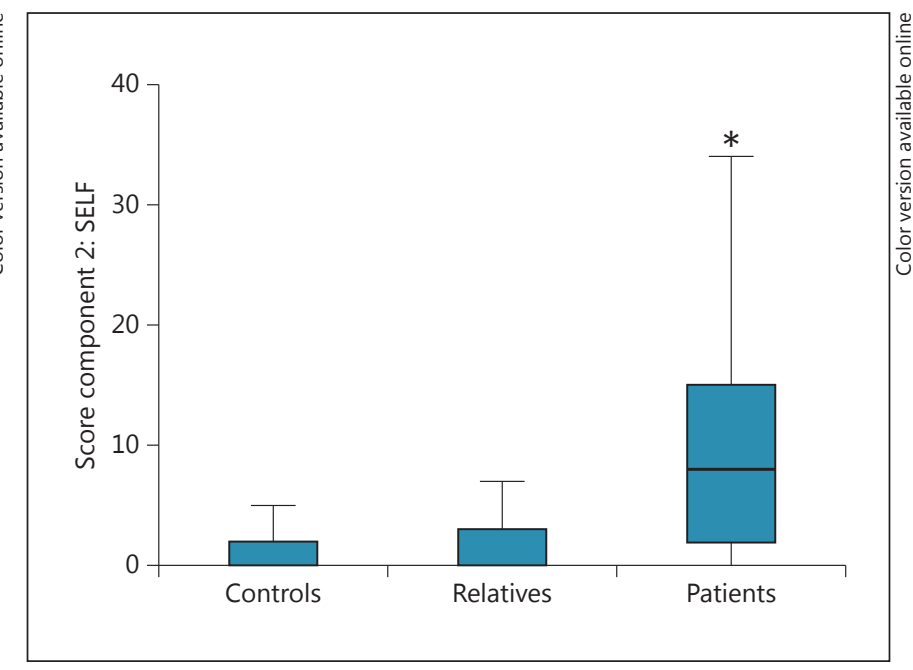

Fig. 2. Distribution of scoring component 2 per participant group. $* \mathrm{p}<0.0001$, mean significant difference.

sonalization, i.e. the items of the DSS. In the EASE these are captured under items 2.2 'distorted first-person perspective' and 2.3 'other states of depersonalization'. Two items loaded on both components, i.e. feelings of diminished presence (feeling as if in a dream) and loss of control (or even ownership) of ones thoughts, emotions or behaviour. These items might measure more than one concept or are caused by more than one underlying latent variable, as is in line with previous research in which different domains of self-disturbance are hypothesized to be interrelated [12].

Our hypothesis that self-disturbances would be more frequently reported and would cause more distress in our patient sample compared to their unaffected siblings and a healthy control group was confirmed. However, we did not find a significant difference between the ratings of siblings and healthy controls. This may suggest that the symptoms of self-disturbance as assessed with the SELF are associated with the clinical status. The fact that the SELF revealed considerably different scores between patients on one side and siblings and healthy controls on the other side suggests that screening of self-disturbance phenomena with the SELF is feasible and possibly clinically relevant. Compared to their healthy siblings and a healthy control group, patients reported different aspects of selfdisturbance not only more often but also causing substantially more distress, which is in line with previous research [29]. In theory, these phenomena may mark the transition from intact reality testing to aberrant reality testing. In clinical practice, talking about these experienc- 
es may lead to more a comprehensive and earlier diagnosis of psychopathology and therewith hopefully to a good working alliance. The SELF may help to introduce the subject of self-disturbance in clinical care concerning patients with a psychotic disorder.

\section{Limitations}

The most important limitation of this study is that we did not include the EASE [2] to test the convergent validity of the SELF with the EASE. The EASE would have been ideal for this purpose, because this elaborate instrument has been used in many studies of self-disturbance in patients with a psychotic disorder. The current study was performed using data pertaining to a large-scale cohort study of psychotic disorders and was not specifically designed for the purpose of validating the SELF. It was thus constrained by the specific instruments used as well as by the composition of the cohort. Regrettably, we were therefore also unable to examine the diagnostic sensitivity of the SELF, i.e. to differentiate dissociative symptoms associated with non-psychotic disorders from those associated with psychotic disorders. However, it is likely that dissociative symptoms occur across different psychiatric disorders. By adding six questions addressing specific symptoms of self-disturbance, derived from the EASE and CAARMS, we attempted to make the SELF a screener sensitive for symptoms of self-disturbance frequently found in patients with psychotic disorders.

Another limitation is a possible restriction in response options and therefore in domains of assessed self-disturbance. Previous research has highlighted the importance of a phenomenological approach towards patients, instead of constraining them to yes or no answers, so as to fully understand their complaints and burden $[7,30]$. However, for routine clinical and research settings a validated short screener for self-disturbances in patients with a psychotic disorder is approachable and feasible and can be used as a first step to more comprehensive examination. Future studies may indicate that it may be necessary to expand the SELF by adding items concerning other domains of self-disturbance.

\section{Conclusion}

Our findings suggest that the items of the SELF cluster in two self-disturbance components, with the first one containing symptoms related to hyperreflectivity and diminished self-affection, and the second compromising symptoms of depersonalization. Patients with a psychotic disorder reported substantially higher scores on both components of the SELF compared to their siblings and a healthy control group, in both frequency and distress. Self-disturbances deserve more attention in clinical settings, because of their burdensome and lasting impact on patients [24], and a short screener like the SELF might help to discover complaints of self-disturbance in clinical practice and research.

\section{Disclosure Statement}

The authors have no conflicts of interest to declare.

\section{References}

1 Sass L, Pienkos E, Nelson B, Medford N: Anomalous self-experience in depersonalization and schizophrenia: a comparative investigation. Conscious Cogn 2013;22:430-441.

-2 Parnas J, Moller P, Kircher T, Thalbitzer J, Jansson L, Handest P, et al: EASE: Examination of Anomalous Self-Experience. Psychopathology 2005;38:236-258.

- 3 Nelson B, Fornito A, Harrison BJ, Yucel M, Sass LA, Yung AR, et al: A disturbed sense of self in the psychosis prodrome: linking phenomenology and neurobiology. Neurosci Biobehav Rev 2009;33:807-817.

4 Parnas J, Handest P: Phenomenology of anomalous self-experience in early schizophrenia. Compr Psychiatry 2003:44:121-134.
5 Lysaker PH, Lysaker JT: Schizophrenia and alterations in self-experience: a comparison of 6 perspectives. Schizophr Bull 2010;36:331340.

6 Haug E, Oie M, Melle I, Andreassen OA, Raballo A, Bratlien U, et al: The association between self-disorders and neurocognitive dysfunction in schizophrenia. Schizophr Res 2012;135:79-83.

7 de Vries R, Heering HD, Postmes L, Goedhart S, Sno HN, de Haan L: Self-disturbance in schizophrenia: a phenomenological approach to better understand our patients. Prim Care Companion CNS Disord 2013; 15:PCC.12m01382.
8 Haug E, Oie M, Andreassen OA, Bratlien U, Raballo A, Nelson B, et al: Anomalous selfexperiences contribute independently to social dysfunction in the early phases of schizophrenia and psychotic bipolar disorder. Compr Psychiatry 2014;55:475-482.

$\rightarrow 9$ Parnas J, Raballo A, Handest P, Jansson L, Vollmer-Larsen A, Saebye D: Self-experience in the early phases of schizophrenia: 5-year follow-up of the Copenhagen Prodromal Study. World Psychiatry 2011;10:200-204.

10 Nelson B, Thompson A, Yung AR: Basic selfdisturbance predicts psychosis onset in the ultra-high risk for psychosis 'prodromal' population. Schizophr Bull 2012;38:1277-1287. 


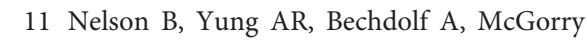
PD: The phenomenological critique and selfdisturbance: implications for ultra-high risk ('prodrome') research. Schizophr Bull 2008; 34:381-392.

12 Nelson B, Whitford TJ, Lavoie S, Sass LA: What are the neurocognitive correlates of basic self-disturbance in schizophrenia? Integrating phenomenology and neurocognition. Part 1. Source monitoring deficits. Schizophr Res 2014;152:12-19.

13 Sass LA: Negative symptoms, schizophrenia, and the self. Rev Int Psicol Ter Psicol 2003;3: 153-180.

14 Parnas J, Handest P, Saebye D, Jansson L: Anomalies of subjective experience in schizophrenia and psychotic bipolar illness. Acta Psychiatr Scand 2003;108:126-133.

15 Simeon D, Guralnik O, Schmeidler J: Development of a depersonalization severity scale. J Trauma Stress 2001;14:341-349.

16 Yung AR, Yuen HP, McGorry PD, Phillips LJ, Kelly D, Dell'Olio M, et al: Mapping the onset of psychosis: the Comprehensive Assessment of At-Risk Mental States. Aust NZ J Psychiatry 2005;39:964-971.
17 Sierra M: Depersonalization: A New Look at a Neglected Syndrome. New York, Cambridge University Press, 2009.

18 Wigman JT, van Winkel R, Jacobs N, Wichers M, Derom C, Thiery E, et al: A twin study of genetic and environmental determinants of abnormal persistence of psychotic experiences in young adulthood. Am J Med Genet B Neuropsychiatr Genet 2011;156B:546-552.

19 Korver N, Quee PJ, Boos HB, Simons CJ, de Haan L; GROUP Investigators: Genetic Risk and Outcome of Psychosis (GROUP), a multi-site longitudinal cohort study focused on gene-environment interaction: objectives, sample characteristics, recruitment and assessment methods. Int J Methods Psychiatr Res 2012;21:205-221.

20 Sierra M, Berrios GE: The Cambridge Depersonalization Scale: a new instrument for the measurement of depersonalization. Psychiatry Res 2000;93:153-164.

21 Sierra M, Baker D, Medford N, David AS: Unpacking the depersonalization syndrome: an exploratory factor analysis on the Cambridge Depersonalization Scale. Psychol Med 2005; 35:1523-1532.

-22 Bullinger M, Alonso J, Apolone G, Leplege A, Sullivan M, Wood-Dauphinee S, et al: Translating health status questionnaires and evaluating their quality: the IQOLA Project approach. Int Qual Life Assess 1998;51:913-923.
23 Sass LA, Parnas J: Schizophrenia, consciousness, and the self. Schizophr Bull 2003;29: 427-444.

24 Kean C: Silencing the self: schizophrenia as a self-disturbance. Schizophr Bull 2009;35: 1034-1036.

25 Costello AB, Osborne JW: Best practices in exploratory factor analysis: four recommendations for getting the most from your analysis. Pract Assess Res Eval 2005;10:173178

26 Kaiser HF: A second generation little jiffy. Psychometrika 1970;45:401-415.

27 Kaiser HF: An index of factor simplicity. Psychometrika 1974;39:31-36.

28 Bartlett MS: A note on the multiplying factors for various $\chi^{2}$ approximations. J R Stat Soc Series B Stat Methodol 1954;16:296-298.

29 Moe AM, Docherty NM: Schizophrenia and the sense of self. Schizophr Bull 2014;40:161168.

30 Nordgaard J, Arnfred SM, Handest P, Parnas $\mathrm{J}$ : The diagnostic status of first-rank symptoms. Schizophr Bull 2008;34:137-154. 